\title{
Opinion of Trainees Regarding Drafting and Paper Pattern Technique
}

\author{
N. Gulati , N. Pruthi , Saroj S. J. Singh and K. Khambra \\ Department of Clothing and Textiles, CCS Haryana Agricultural University Hisar, \\ Haryana, India
}

KEYWORDS Drafting Technique. Paper Patterns. Opinion. Trainees

\begin{abstract}
Twelve paper patterns(9 kameez \& 3 salwar) were standardized for pre adolescent girls. To study the opinion of the trainees regarding drafting and paper pattern technique, four trainings each of one-week duration in cutting and stitching of kameez-salwar for pre-adolescent girls were conducted. Two trainings were conducted in urban area and two in rural areas of Hisar. Opinion of trainees regarding paper patterns highlighted that with the use of paper patterns, trainees were able to stitch kameez-salwar independently at home. The trainees also opined that garment construction can be taken up as an income generating activity if paper patterns of different sizes are easily available. Majority of trainees had high opinion about paper patterns on the other hand $63.33 \%$ had low opinion about drafting technique because illiterate ladies with low educational level could not do calculations for drafting and taking body measurements was also a difficult task hence drafting of kameez-salwar could not be done properly.
\end{abstract}

\section{INTRODUCTION}

Garment construction at home not only saves money, it also provides proper fitting if garments are stitched carefully. For that a proper drafting technique is to be used based on accurately taken body measurements. It has been observed that women generally acquire skill in stitching but cutting remains a problem because traditional method of cutting through drafting technique is very time consuming process. Drafting means to draw or sketch outline of something to be done on paper. It is ready size of any garment, made according to an individual's measurements. It needs too many calculations as a result it becomes difficult for women with low educational level to do drafting properly to stitch garments of every size having prorer fitting.

To make garment cutting an easy process for such women, standardized paper patterns have been developed of kameez-salwar for preadolescent girls. Paper pattern means model or design of something made on a paper. Paper pattern of master size is specifically designed for a particular type of figure and has to be accurate as per the bust size of the population on the basis of anthropometric measurements (Aggarwal 1998).

Development of standardized paper pattern

Address correspondence to:

Neelam Pruthi,

165-Sector 15A, Hisar, Haryana 125 001, India

E-mail: neelam_pruthi@yahoo.co.in will not be of any use until and unless these are popularized among the target group. With this objective in mind, trainings were organized. It has been rightly remarked that training appears to be an invisible input, but their results are highly visible therefore such programmes may be organized frequently to boost up the socioeconomic development and for inducing the behavioral changes. (Mahale et al. 1991)

To find out the usefulness of paper patterns, comparative opinion of the women regarding drafting and paper pattern technique was also studied. Opinion is a view, judgment or appraisal formed in the mind about a particular matter that should be kept to you. In other words opinion applies to a conclusion or judgment, while it remains open to dispute, seems true or probable to one's own mind. Analyais of women's opinion regarding drafting and paper pattern technique has been highlighted in the present paper.

\section{METHODOLOGY}

To study the comparative opinion for drafting and paper pattern technique the various steps taken were as follows:

Organization of Training: To investigate the opinion of the trainees regarding drafting and paper pattern, four trainings each of one-week duration were organized, two in Hisar city and two in selected villages. Each group had minimum of 10 trainees and a total of 60 trainees attended the training. 
Imparting Training: The trainees who had some knowledge of stitching were selected for the training. They were taught the drafting technique and use of paper patterns for cutting of kameez-salwar for pre-adolescent girls. Each trainee stitched two sets of kameez-salwar one using drafting technique and another with the help of standardized paper pattern. Both the kameezsalwar were tried for fitting assessment.

Opinion of Trainees: Opinion of trainees regarding drafting and paper pattern technique was studied using an interview schedule developed under research project by the department. After the training, opinion of trainees were sought on three point continuum scale i.e. agree, somewhat agree and disagree scoring 3,2 $\& 1$ respectively.

Analysis of Data: Percentage was calculated to study the personal profile of the trainees and weighted mean score (WMS) was calculated to find out the opinion of trainees regarding drafting and paper pattern technique and ranking was done. The opinion level was also calculated on the basis of the total score.

\section{RESULT AND DISCUSSION}

Information about the trainees and their opinion has been presented as under:

Personal Profile of the Trainees: An attempt was made to compile personal attribute of trainees regarding age, education, family size and income which has been presented in table 1 .

Age: The data elucidated that $51.66 \%$ trainees were in the age group of 15-25 years followed by

Table 1: Personal profile of the trainees $(\mathrm{N}=60)$

\begin{tabular}{lrc}
\hline Personal attributes & Frequency & Percent \\
\hline Age (in Years) & 31 & \\
15- 25 & 24 & 51.66 \\
25-35 & 5 & 08.00 \\
35-45 & 8 & 13.33 \\
Education & 24 & 40.00 \\
$\quad$ Illiterate & 17 & 28.33 \\
Middle & 3 & 05.00 \\
High School & 8 & 13.33 \\
Graduate & & \\
Technical & 2 & 03.33 \\
Family Size (No. of Members) & 43 & 71.66 \\
Less than 4 & 15 & 25.00 \\
5-7 & & \\
$\quad$ More than 7 & 12 & 20.00 \\
Income (Rs./Month) & 31 & 51.66 \\
$\quad$ Upto 3000 & 17 & 28.33 \\
3001-6000 & \\
$\quad$ 6001-9000 & & \\
\hline
\end{tabular}

$40.00 \%$ trainees who were in the age group of $25-$ 35 years and only $8.36 \%$ trainees were in the age group of 35-45 years.

Education: The information related to the education indicated that $40.00 \%$ trainees had received education till middle class whereas $28.33 \%$ trainees had education unto secondary level, $13.33 \%$ had technical education related to garments construction, $13.33 \%$ were illiterate and only $5.00 \%$ were graduates.

Family size: As per the description of family size, $71.66 \%$ of trainees were from medium sized family (5-7 members) followed by $25.00 \%$ and $03.33 \%$ respondents who belonged to large and small families respectively.

Income: The information about the income revealed that $51.66 \%$ had monthly income in the range of Rs. 3001-6000 and $28.33 \%$ were earning in the range of Rs. $6001-9000$ where as only $20.00 \%$ trainees were having monthly income upto Rs. 3000 .

Opinion of the Trainees Regarding Drafting Technique: Data depicted in table 2 about opinion of the trainees regarding drafting technique revealed that the trainees did not have high opinion about drafting. The opinion statements - 'illiterate ladies with low educational level can't do calculations for drafting' was ranked $1^{\text {st }}$ as it scored highest i.e. 2.90 followed by 'taking body measurements is a difficult task hence drafting of kameez-salwar can't be done properly' ranking $\mathrm{II}^{\text {nd }}$ with a score of 2.80 ,'drafting technique is very difficult as it needs too many calculations' ranked III $^{\text {rd }}$ scoring 2.73 .

Other reasons for poor opinion about drafting technique found in descending rank order were: 'proper fitting of kameez-salwar is not possible without knowledge of appropriate drafting technique' (2.71), 'one has to depend on others for cutting of kameez-salwar if its drafting is not known' (2.70), 'drafting technique is very time consuming process' (2.66). Few trainees were also of the opinion that 'one must learn drafting technique to cut kameez-salwar of any size' ranked $\mathrm{VII}^{\text {th }}$ and 'drafting technique is the best method for cutting of kameez-salwar' VIII ${ }^{\text {th }}$ as these scored very low i.e. 2.18 and 2.16 respectively.

A very few trainees opined that 'for cutting of kameez-salwar one should always follow drafting technique' as it scored only 1.80 and 'drafting can only be practiced by women of any education level' ranking $X^{\text {th }}$ The findings were in conformity with findings of Singh et al. (1995), Devi (2006) and Sharma (2006) 
Opinion Level of Trainees Regarding Drafting Technique: It is evident from figure 1 that a few trainees $(16.66 \%)$ had high level of opinion regarding drafting and $20.00 \%$ respondents had moderate opinions whereas $63.33 \%$ had low opinion about this technique. Opinion level of the respondents with reference to drafting technique was in conformity with findings Devi (2006) and Sharma (2007)

From the data in the table 2 and figure 1 can be concluded that though the trainees felt that taking body measurements was a difficult task and doing drafting was a time consuming process inspite of that a few number of trainees were of the opinion that one must learn drafting technique as it is a best method to do cutting of kameezsalwar. This might be due to the reasons that the trainees were very much versatile with drafting

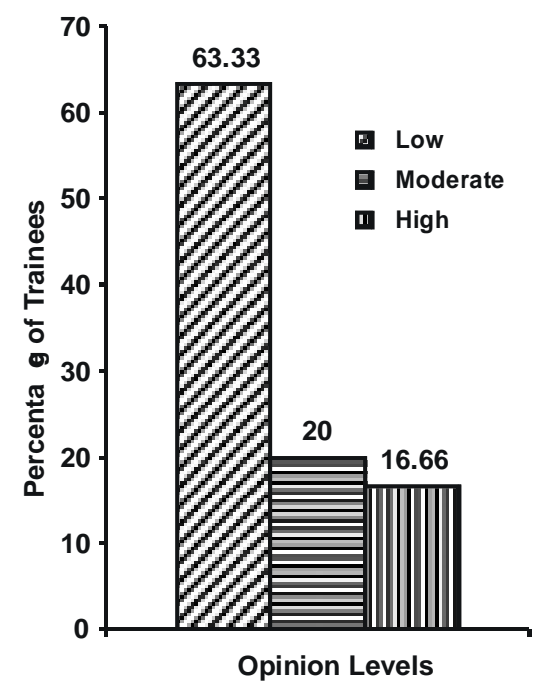

Fig. 1. Opinion level of trainees regarding drafting technique technique and a few of them had also received technical knowledge in garment construction.

Opinion of Trainees Regarding Paper Pattern Technique: From the data regarding opinion of trainees for paper patterns revealed that trainees had high opinion about the paper patterns because 'use of paper patterns have given chance to stitch kameez-salwar at home' scored highest i.e. 2.95 ranking $1^{\text {st }}$ and 'one can adopt garment construction as an income generating activity if paper patterns of different sizes are easily available' 2.92 ranking IInd (Table 3 ). Other reasons found in descending rank order were: "with the help of paper patterns, one can do cutting independently' (2.88), 'the paper patterns will increase the speed of garment construction' (2.86), 'kameez-salwar stitched by using paper patterns has very good fitting' (2.80), 'it is worth spending money on paper patterns of kameez-salwar' (2.50), 'by using appropriate paper patterns the trainees will be able to stitch garments of any family member' (2.40) 'if paper patterns are easily available, no need to learn drafting technique' (2.33), 'it is economical and time saving to use paper patterns' (2.23) and 'paper patterns must have both cutting and stitching lines to have uniform seam allowances' (1.81).

It is evident from the results that a very few trainees were of the opinion that, 'drafting can be done free of cost no need to spend money on paper patterns' scoring1.66 and ranking XI, ' no need to spend money on paper patterns of other garments' was ranked XII with a score of 1.66 'paper patterns are of no use as different sizes are required for different garments' was ranked at XIII position scoring (1.53).

Aggarwal and Gupta (2005) Pruthi et al. (2006) and Devi (2006) also found that it was easy to cut and stitch garments by using paper patterns

Table 2: Opinion of trainees regarding drafting technique $(N=60)$

\begin{tabular}{|c|c|c|}
\hline Statements & $W M S$ & Rank \\
\hline For cutting of kameez-salwar one should always follow drafting technique & 1.8 & $\overline{I X}$ \\
\hline Drafting technique is the best method for cutting of kameez-salwar & 2.16 & VIII \\
\hline One has to depend on others for cutting of kameez-salwar if its drafting is not known & 2.70 & V \\
\hline Proper fitting of kameez-salwar is not possible without knowledge of appropriate drafting technique & 2.71 & IV \\
\hline Taking body measurements is a difficult task hence drafting of kameez-salwar can't be done properly & 2.80 & II \\
\hline Drafting technique is very difficult as it needs too many calculations & 2.73 & III \\
\hline Drafting technique is very time consuming process & 2.66 & VI \\
\hline Illiterate Ladies with low educational level can't do calculations for drafting & 2.90 & I \\
\hline Drafting can only be practiced by women of any education level & 1.30 & $\mathrm{X}$ \\
\hline One must learn drafting technique to cut kameez-salwar of any size & 2.18 & VII \\
\hline
\end{tabular}

WMS- Weighted mean score 
Table 3: Opinion of the trainees regarding paper pattern technique $(\mathrm{N}=60)$

\begin{tabular}{lrr}
\hline \multicolumn{1}{c}{ Statements } & WMS & Rank \\
\hline With the help of paper patterns, one can do cutting independently & 2.88 & III \\
Use of paper patterns does not save time during cutting & 1.06 & XVI \\
The paper patterns will increase the speed of garment construction & 2.86 & IV \\
Kameez-salwar stitched by using paper patterns has very good fitting & 2.80 & V \\
It is worth spending money on paper patterns of kameez-salwar & 2.50 & VI \\
No need to spend money on paper patterns of other garments & 1.66 & XII \\
Paper patterns are of no use as different sizes are required for different garments & 1.53 & XIII \\
By using appropriate paper patterns the trainees will be able to stitch garments of & 2.40 & VII \\
any family member & & \\
One can adopt garment construction as an income generating activity if paper patterns & 2.91 & II \\
of different sizes are easily available & 1.15 & XV \\
Kameez-salwar stitched with paper patterns do not have satisfactory fitting & 2.33 & VIII \\
If paper patterns are easily available, no need to learn drafting technique & 2.23 & IX \\
It is economical and time saving to use paper patterns & 1.80 & XI \\
Drafting can be done free of cost no need to spend money on paper patterns & 1.33 & XIV \\
Maintenance of paper patterns is very difficult & 2.95 & I \\
Use of paper patterns have given chance to stitch kameez-salwar at home & 1.81 & X \\
Paper patterns must have both cutting and stitching lines to have uniform seam allowances. & &
\end{tabular}

WMS- Weighted mean score

because it was found to be time saving technology and it also provided good fitting.

Opinion Level of Trainees Regarding Paper Pattern Technique: Data depicted in figure 2 revealed that majority of trainees $(76.66 \%)$ had high opinion about paper patterns while only $23.33 \%$ had moderate opinion and none of the trainees had low opinion about paper patterns. Opinion level of the respondents with reference to paper pattern technique was in conformity with findings of Devi (2006) and Sharma (2006).

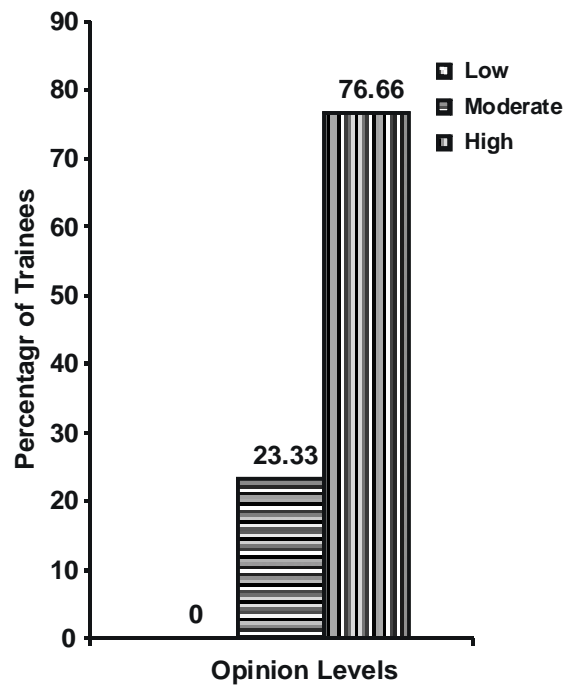

Fig. 2. Opinion level of trainees regarding paper pattern technique

\section{CONCLUSION}

From the study it can be concluded that paper pattern were found to be an easy and time saving technology. To promote home sewing paper patterns must be popularized. These must be available in different sizes to the women engaged in tailoring so that they can take up this activity to earn money for welfare of their families.

Home sewing can be promoted if paper patterns are provided was reported by Singh et al. (1995), Grover (1997), Sharma and Kaur (2003), Sharma (2004) and Aggarwal and Gupta (2005).

\section{REFERENCES}

Aggarwal A 1998. Grading and Sizing: Important in Readymade Garments. Text Trade J, 6(3): 32-38

Aggarwa R, Gupta V 2005. Development of Commercial paper patterns for Ladies Kurtas a Need Based. Papers presented and published in book on National Textile Seminar on Industry-Institutes Interface Technology Development. Lady Irwin College, Delhi. November 23 to 25: $108-110$

Devi P 2006. Standardization of Paper Patterns of Blouse. M. Sc. Thesis (Unpublished), Haryana: CCS Haryana Agricultural University Hisar.

Grover D 1997. Designing, Developing, Paper Patterns and Construction of Sari-Blouses for Women Between the Age of 25-30 Years M. Sc. Thesis (Unpublished), Haryana: Kurukshetra University.

Mahale G, Gavimathu U Varghese G 1991. Impact of Tailoring Training Programme on Knowledge Level of rural Women, Maha Jour Extn Edu, 10(2): 320-322

Pruthi N, Singh SS Jeet, Khambra K 2006, PaperPatterns- An Easy Technology for Garment Construction. Paper presented in National Conference on Range and Scope of Skill 
Development for Empowerment of Rural/Deprived Women by Vigyan Samiti. Udipur, March 18 to 20. Sharma A, Kaur R 2003. Paper-Pattern--An Aid of Popularizing Art of Sewing. Textile Trends, XLVI (8): $35-36$.

Sharma S 2004. Standardization and Development of Paper Patterns for Adolescent Top. M. Sc. Thesis (Unpublished), Haryana: CCS Haryana Agricultural University, Hisar.
Sharma S 2006. Standardization of Paper Patterns of Kurta-Pyajama for Pre-Adolescent Boys. M. Sc. Thesis (Unpublished), Haryana: CCS Haryana Agricultural University, Hisar.

Singh SS Jeet, Pruthi N and Khambra K 1995. Report on research project: Standardization of Paper Patterns for Promotion of Garment Construction Amongst Rural Women Entrepreneurs. Department of Clothing and Textile, CCS HAU, Hisar. 